\title{
Solar photovoltaic self-consumption in the UK residential sector: new estimates from a smart grid demonstration project
}

\author{
Eoghan McKenna ${ }^{1}$, Jacquelyn Pless ${ }^{2}$, and Sarah Darby ${ }^{1}$ \\ ${ }^{1}$ Environmental Change Institute, School of Geography and the Environment, University of \\ Oxford, South Parks Road, OX1 3QY, UK \\ ${ }^{2}$ Institute for New Economic Thinking, University of Oxford, Eagle House, Walton Well Road, \\ Oxford, OX2 6ED, UK
}

Accepted submission to Energy Policy. Published article available here: https://doi.org/10.1016/j.enpol.2018.04.006

\begin{abstract}
The economic incentive to install a solar photovoltaics ('PV') system depends increasingly on using PV generation on-site ('self-consumption') rather than receiving payments from generating solar energy and exporting it to the grid. There is, however, remarkably little empirical evidence on self-consumption. This paper begins to address this gap by analysing one-minute electricity monitoring data for 302 households that participated in a UK smart grid demonstration project. We calculate annual self-consumption levels and find that they are $855 \mathrm{kWh} /$ year per household on average, or $45 \%$ of PV generation. We conduct a simple regression analysis to estimate self-consumption and use the results to show that self-consumption for an average UK household with electricity demand of $4000 \mathrm{kWh} /$ year and $2.9 \mathrm{kWp}$ PV system would be $966 \pm 38 \mathrm{kWh} /$ year, equivalent to a $24 \%$ reduction in average annual electricity demand from the grid. Our methodology can be readily applied to measure and predict self-consumption in other solar markets as well, which has increasingly important implications for valuing solar investments, setting feed-in tariffs, and examining the impacts of PV on networks and retail sales.
\end{abstract}

Keywords: photovoltaic; solar; self-consumption; feed-in tariff; prosumer. 


\section{Introduction}

Addressing climate change and reducing greenhouse gas emissions will require a rapid transition to electricity systems that are sustainable, affordable, and secure (Edenhofer et al., 2014; Pfeiffer et al., 2016). Solar photovoltaics ("PV") will almost certainly play a major role as a provider of zero carbon electricity (Carbon Tracker and Grantham Institute, 2017; Taylor et al., 2015). In the UK specifically, it has the highest level of public support of all low-carbon electricity generation technologies (BEIS, 2017a) and is expected to be the cheapest form of electricity generation by 2025, alongside onshore wind (Figure 1). As of April 2017, over $12 \mathrm{GW}$ of solar photovoltaics had been deployed, of which roughly $2.5 \mathrm{GW}$ comes from small $<4 \mathrm{~kW}$ units associated with homes and small businesses and a further 4GW from 4kW-5MW arrays. (BEIS, 2017b). The trend is clear: solar PV is set to make a major contribution to UK electricity supply, and a substantial proportion of solar capacity will be highly-distributed.

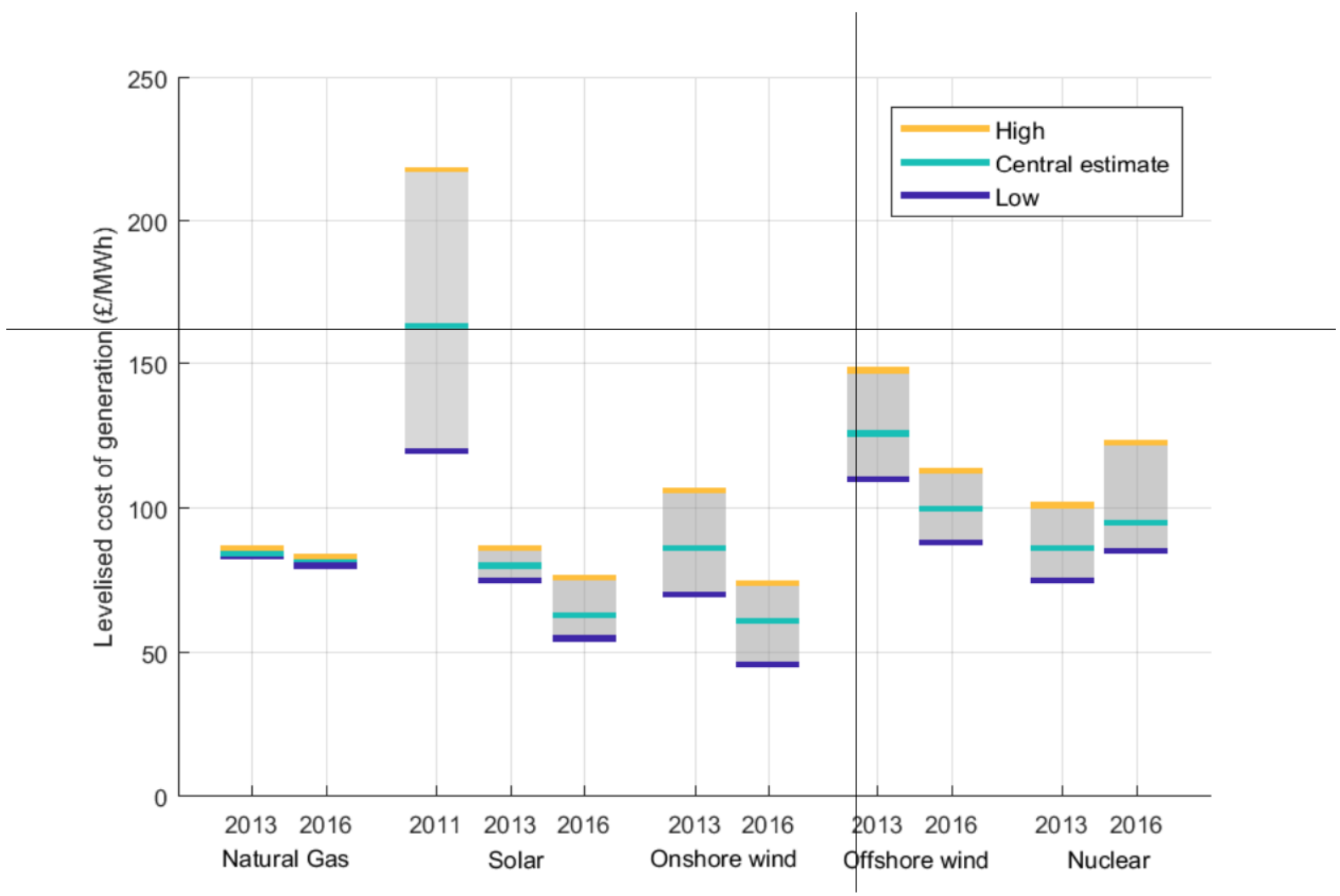

Figure 1 - forecasts of comparable costs of electricity generation in Britain for 2025. Dates show year forecasts were published. Data from (Arup, 2011; BEIS, 2016a; DECC, 2013 ). 
Nonetheless, PV adoption in the UK residential sector has fallen dramatically from its peak rate of more than 55,000 installations per month in November 2011 to 2,000-3,000 per month in early 2017 (Figure 2). This is at least partially in response to reductions in the government subsidy for residential PV - the feed-in tariff. The UK feed-in tariff has two components: a 'generation rate', which is a payment for each kWh generated by the PV (regardless of whether it is exported or used within the home), and an 'export rate', which is a payment for each kWh exported to the grid. Since its inception in April 2010, the UK government has progressively lowered the generation rate to reflect PV's falling capital costs (although the export rate has risen very slightly) (Figure 2$)^{1}$

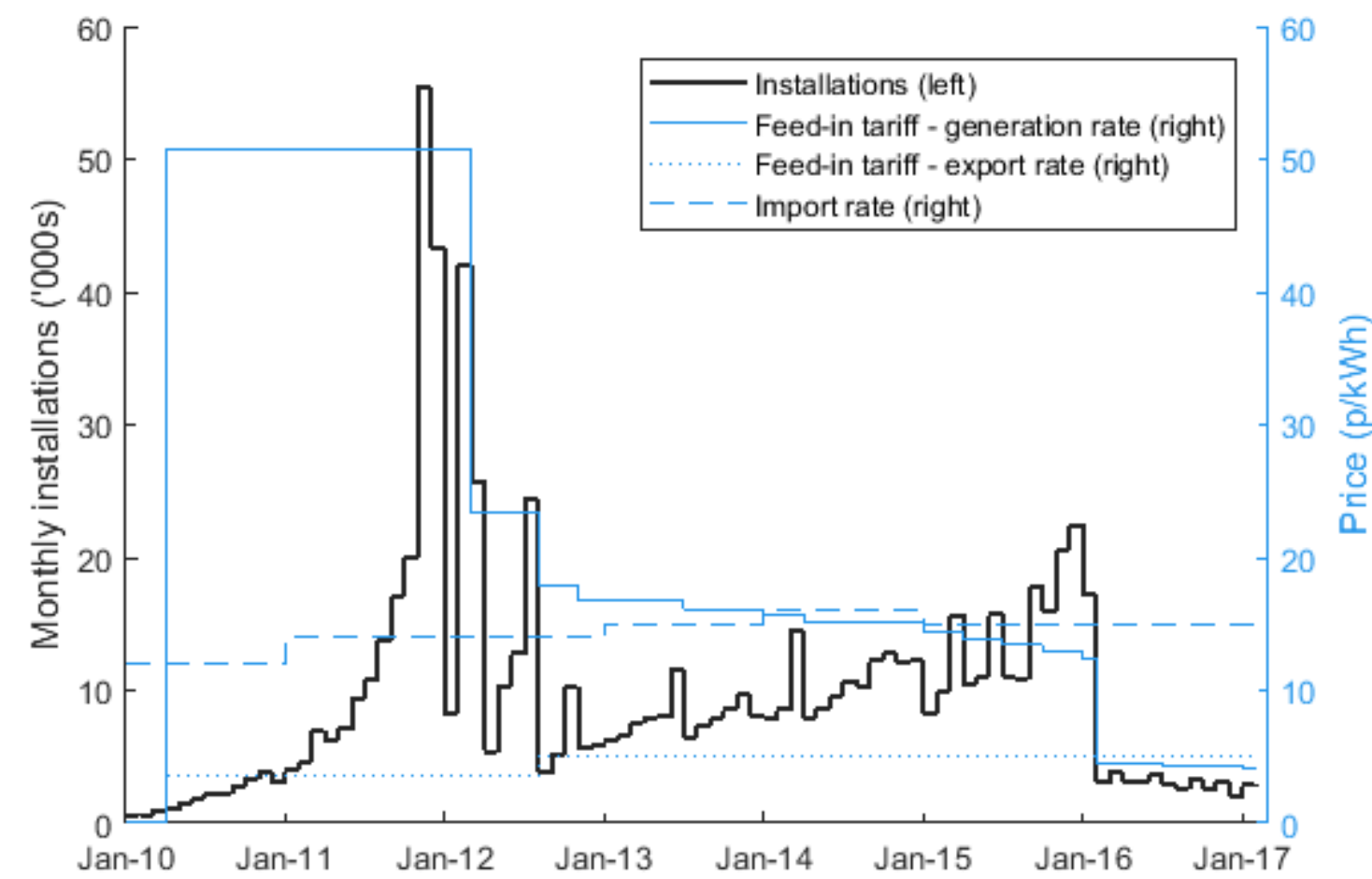

Figure 2 - trends in deployment and feed-in tariff for residential PV in the UK. Typical residential import rate (retail price of electricity) also shown. Monthly installations from (BEIS, 2017c), feedin tariff rates from (Ofgem, 2017) and import rates from (BEIS, 2017d; DECC, 2016).

\footnotetext{
${ }^{1}$ Note the peaks in installations immediately before each drop in the generation rate. This reflects consumers rushing to adopt solar before an anticipated subsidy drop and suggests the subsidy levels at least partially impacted installation rates.
} 
Historically, the export rate has been low relative to the typical retail price of residential electricity (the 'import rate'). Because of this, in theory, households with PV benefit from shifting load from hours when they face import tariffs to hours when their PV is generating ${ }^{2}$. In other words, households with PV benefit from maximizing consumption of their own system's generation (i.e., 'self-consumption') when the export rate is lower than the import rate. The reverse is true if the export rate exceeds the import rate: households with PV would benefit from minimising self-consumption. Furthermore, the decline of the generation feed-in tariff rate has made maximizing self-consumption even more important-as the FiT historically played a significant role in determining solar investment payback, electricity bill savings (achieved through self-consumption) make up an increasing proportion of the overall returns to solar investment. Figure 3 illustrates the relevant power flows for understanding self-consumption.
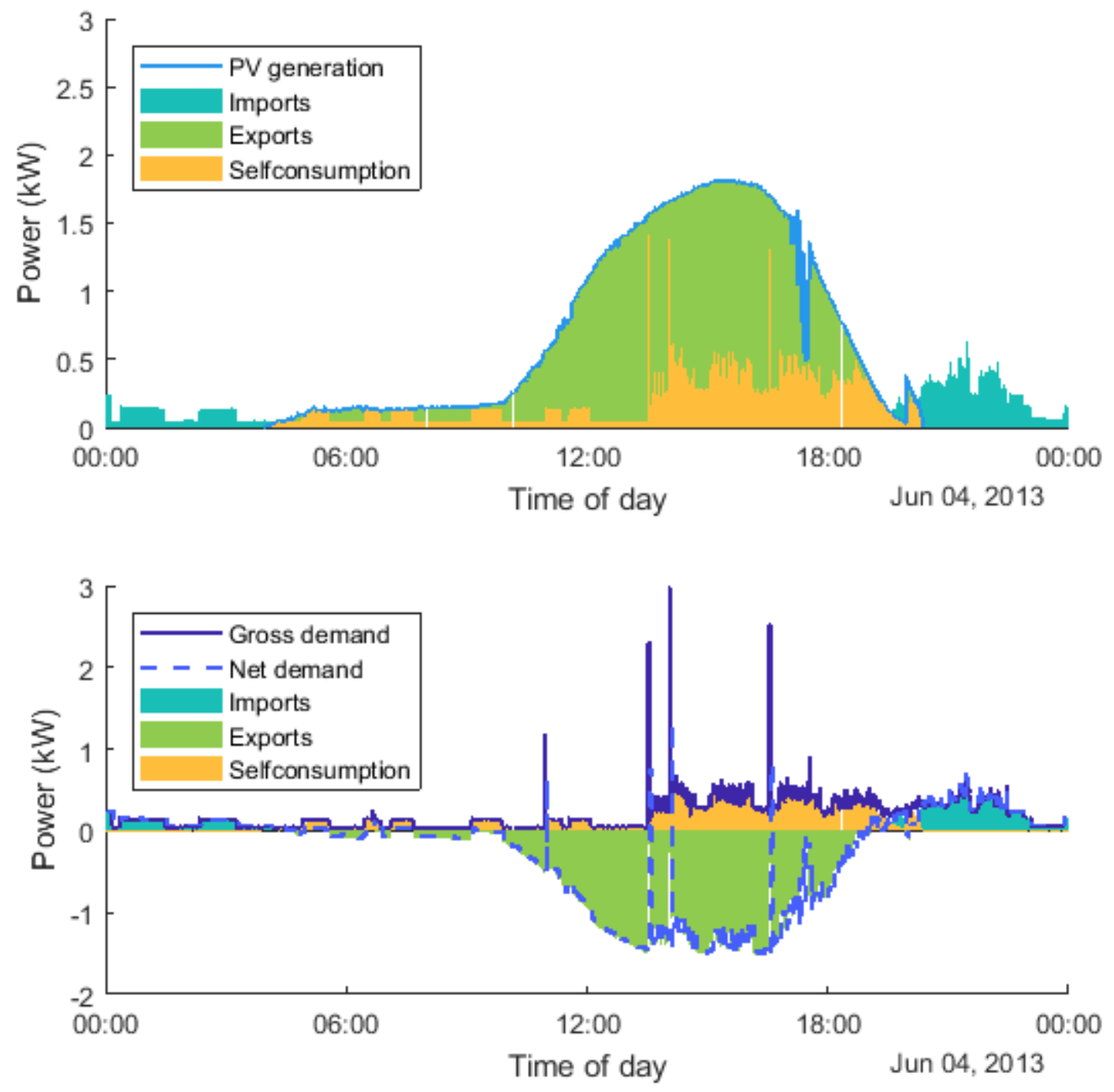

Figure 3 - electrical power flows for a summer day for an example residential household with PV in UK. Data from (CLNR, 2017).

${ }^{2}$ A summary of typical feed-in tariff and metering configurations in the UK and other countries and how they incentivise different types of demand response behaviour can be found in McKenna and Thomson $(2013,2014)$. 
As noted, households with PV in general have a strong incentive to maximise self-consumption when import rates exceed export rates because of the electricity bill savings accrued when load is shifted from times of the day when it would otherwise face import tariff rates. However, households with PV in the UK have an even stronger incentive to self-consume due to a lack of smart metering for exports. ${ }^{3}$ Exports are not directly measured but rather 'deemed' to be $50 \%$ of generation. As such, the financial benefit from exporting solar power to the grid (which should be excess generation as a function of the household's consumption and solar generation) is strictly a function of solar generation only (and the static $50 \%$ export assumption). Until smart meters are rolled out with the capacity to measure imports and exports in near-real-time, and dynamic pricing and half-hourly settlement are established, any electricity produced by domestic PV and used within the home is essentially free (zero marginal cost). ${ }^{4}$

As feed-in tariffs decrease and self-consumption plays a more important role in the economics of PV, potential PV adopters face greater uncertainty about the expected return on their investment, as this depends not only on estimating PV generation but also self-consumption. Therefore, estimating and predicting PV self-consumption can help potential adopters make informed judgements about their potential return on investment by reducing the amount of electricity they import from the grid.

Estimating self-consumption and predicting the resulting electricity bill savings are also critical for policymakers, as electricity bill savings estimates are often used to calculate the appropriate feed-in tariff rate to achieve PV deployment targets (DECC, 2015a). This is a particularly timely topic in the face of retail electricity price increases and regulatory changes. For example, in 2015, the UK government consulted on a review of the feed-in tariff scheme to ensure that deployment and spending were brought under control, and that generators were 'not making excessive returns on their investments' (DECC, 2015b). The review included an assessment and call for further evidence on the government's assumed self-consumption rate of $50 \%$ (relative to PV generation) for residential systems. The response to the consultation concluded there was 'little usable evidence' (DECC, 2015a, p. 31), despite over 800k residential PV systems in the UK (BEIS, 2017c). Based on the limited evidence available, the range of self-consumption rates was assumed to be $25 \%-45 \%$ and a deliberately high value of $45 \%$ was chosen to 'encourage those installations that make most use of the renewable electricity generated' (DECC, 2015a, p. 31). There are also other markets around the world where self-consumption is becoming the main economic driver for solar, such as in Germany, France, and Spain (Labastida, 2017).

Lastly, self-consumption is also important for examining how increasing penetration of intermittent renewable electricity impacts electricity grids and for predicting retail sales. The challenge of balancing supply and demand of electricity on the high-voltage grid in real-time has been made more difficult as the growing volume of PV generation is connected to the distribution network and its output is effectively invisible to the system operator. Difficulties in forecasting PV generation mean there are real risks of periods with too much generation (National Grid, 2017), as well as sudden drops in generation due to widespread cloud cover, both of which increase the burdens on (and costs and emissions of) conventional thermal generation. Medium- and low-voltage networks are also impacted. Distribution networks today face the unprecedented problem of connected generation exceeding demand (WPD, 2016) and may resort to limiting new PV connections until networks are reinforced and/or storage and demand response are implemented.

Given the expectation of continued PV deployment, there is increasing need to better understand the impact it has on electricity networks. In this context, self-consumption is important because the extent to which households change behaviour to make use of PV generation directly affects net demand profiles (gross demand minus PV generation) and power flows on networks (Figure 3).

\footnotetext{
${ }^{3}$ To be clear, we are not referring to a lack of smart meters in the general population, but a lack of consumers with PV registered for FiTs that are recorded as having metered exports rather than deemed exports.

${ }^{4}$ If half-hourly settlement and smart metering are introduced, the picture becomes more complicated, but still there will be an incentive to self-consume as long as import rates are higher than export rates, and assuming there is no opportunity cost of shifting load to different times of the day.
} 
However, there remains little evidence-based research on self-consumption to support consumers, policy, and industry. A standard method for estimating self-consumption and predicting electricity bill savings that can be broadly applied is needed, which is the focus of this paper. We examine self-consumption in the UK solar market context using data from a major smart grid demonstration project completed by Northern Powergrid, a UK distribution network operator, in 2014: the Customer Led Network Revolution ('CLNR') (NPG, 2017). Part of the project consisted of a long-term metering campaign of over 300 residential households in the North East of England that measured PV generation and net demand (CLNR, 2013). The project team analysed these data and found average annual self-consumption to be $80-82 \%$ per household (CLNR, 2013, pp. 13-14), which is substantially higher than the 25\%-45\% range found in other studies. It turns out that the methodology introduced substantial error as self-consumption was calculated as a sum of averages rather than an average of the sums. The CLNR estimates of the average aggregated over many households, therefore, can be interpreted as the 'after diversity' self-consumption per household; for example, self-consumption at a low-voltage substation if an entire low-voltage feeder was populated by households with PV. The project did not provide an analysis of disaggregated household level data or the factors that affect self-consumption, nor did it examine how self-consumption varies by household.

As such, it is our aim to close some of these gaps and estimate self-consumption based upon household-level average self-consumption. We also analyse factors that affect self-consumption and compare our results with other empirical studies of UK households with PV. Lastly, we develop a predictive model for selfconsumption based upon household PV generation and electricity demand to predict self-consumption for the average UK household with PV and infer the associated electricity bill savings. Our findings suggest that UK households with PV self-consume $45 \%$ of their own solar generation on average and reduce annual electricity demand from the grid by $24 \%$, which implies $£ 138 /$ year in electricity bill savings per household.

\section{Methods and data}

2.1. Calculating self-consumption

Household self-consumption is electrical demand that occurs at times when PV is generating but does not exceed its output. As previously noted, Figure 3 provides the relevant electrical power flows for calculating self-consumption using data for a real household with PV, where self-consumption is shown in yellow. The top figure shows the electrical output from a $\sim 2 \mathrm{~kW}$ roof-top PV system over the course of a single summer day. The gross electricity demand from the household is shown in the bottom figure (dark blue line). Due to the presence of the PV system, only part of the gross demand is imported from the grid (shown in turquoise). Any surplus PV generation is exported to the grid (green). The net demand profile (light-blue dashed line, bottom figure) shows the net power flow from the grid to the household. To calculate these variables for a real system, two concurrent time-series of data are required: PV generation and net demand. The other variables can be calculated as shown in Table 1.

\section{Table 1 - description of measured and derived variables.}

\begin{tabular}{ll} 
Variable & Description \\
\hline \hline$P_{p v}$ & PV generation $(\mathrm{kW})$. Measured. \\
$P_{n e t}$ & Dwelling's net power flow $(\mathrm{kW})$. Measured. \\
$P_{i}=\max \left(P_{n e t}, 0\right)$ & Electricity demand imported from the grid $(\mathrm{kW})$. Derived. \\
$P_{e}=-\min \left(P_{n e t}, 0\right)$ & $\mathrm{PV}$ output exported to grid $(\mathrm{kW})$. Here exports to the grid \\
& are treated as positive power flows. Derived. \\
$P_{\text {gross }}=P_{n e t}+P_{p v}$ & Dwelling's gross electricity demand $(\mathrm{kW})$. Derived. \\
$P_{\text {self }}=P_{p v}-P_{e}$ & Self-consumption $-\mathrm{PV}$ generation that is consumed on- \\
& site within the dwelling $(\mathrm{kW})$. Derived. \\
\hline
\end{tabular}




\subsection{Description of data}

The CLNR dataset analysed here consists of two of the project's 'test cells': TC5 and TC20IHD. Both are made up of households with PV located in the north east of Britain, where Northern Powergrid's network is located. TC5 consists of 155 households with PV, while TC2OIHD consists of 147 households with PV who were also given an in-home display that indicated when PV generation exceeded demand and was being exported to the grid. Each household was fitted with meters that recorded PV generation and net electricity demand at 1 min resolution in units of average power (kW). The full date range for the data was April 2012 to March 2014 , though each household had different start and end dates. The data is available via the project's website. $^{5}$

The data is anonymised, and no socio-demographic details were published about the participants except that they were predominantly a mix of owner-occupiers and social tenants. Participants were recruited with an offer of a subsidy of a $£ 50$ voucher at the start and end of the trial. Compared to the project's control group - a representative group of $>8700$ residential consumers with smart meters (CLNR, 2014a) - they were found to have higher levels of overall electricity demand, were more likely to have very high levels of demand, used a higher proportion of electricity during the evening peak, and used more electricity during the day (Bulkeley et al., 2015; CLNR, 2013). A final set of 218 systems is used in this analysis (i.e. 28\% of systems were rejected in total due to missing data and other errors). The steps taken to prepare the data are detailed in the Appendix.

\subsection{Estimating self-consumption for a typical UK household with PV}

The last aim of this paper is to provide a simple and straightforward way to estimate self-consumption for a typical UK household with PV. To do this, we use an ordinary least squares regression approach to estimate how much of self-consumption is explained by annual PV generation, annual gross electricity demand, and fraction of day-time electricity usage on average based on the CLNR data. Our aim is not to estimate any causal relationships between the explanatory variables and self-consumption, nor is it to develop a model of many predictor variables that can fully explain all of the variation in self-consumption. Rather, we aim to estimate how much of the variation in self-consumption can be explained by a few pieces of data on electricity use and solar generation that are potentially available for PV households. This allows us to then use the estimates of the model to calculate the expected self-consumption for the average PV household in the UK, and it also allows us to demonstrate a very simple approach that can be more readily applied in other markets where the data exist.

We estimate the following simple linear model:

$$
E_{i}^{\text {self }}=\beta_{0}+\beta_{1} E_{i}^{p v}+\beta_{2} E_{i}^{\text {gross }} f_{i}^{\text {day }}+u_{i}
$$

Equation 1

where $E_{i}^{\text {self }}$ is annual self-consumption for household $i(\mathrm{kWh} / \mathrm{yr}), E_{i}^{p v}$ is annual PV generation for household $i$ $(\mathrm{kWh} / \mathrm{yr}), E_{i}^{\text {gross }}$ is annual gross electricity demand for household $i(\mathrm{kWh} / \mathrm{yr}), f_{i}^{d a y}$ is the average annual fraction of electricity usage during day-time (10am- $4 \mathrm{pm})$, and $u_{i}$ is an error term. We then use these model results to predict self-consumption and the implied demand reduction and electricity bill savings for a typical household using values for a typical UK household with PV, which we detail in Section 4.

\section{Results and discussion}

The results of the analysis show that the CLNR households with PV, on average, self-consume $45 \%$ of the PV that is generated onsite. This is substantially lower than the project's official estimates of $80 \%-82 \%$, however it is within the range of other self-consumption estimates. In this section, we present the details of our results, discuss their implications, and further explore heterogeneity in self-consumption.

\footnotetext{
${ }^{5}$ http://www.networkrevolution.co.uk/resources/project-data/
} 


\subsection{Main Results}

The CLNR households with PV studied here had an average annual gross electricity demand of $4366 \mathrm{kWh} / \mathrm{yr}$, compared to the control group's $3570 \mathrm{kWh} / \mathrm{yr}$, confirming the finding that households with PV tend to have higher than average consumption (DECC, 2015c). Average PV generation was $1942 \mathrm{kWh} / \mathrm{yr}$. Of the 170 households where PV system size data were available, the average size of PV system was $1.95 \mathrm{~kW}$, which is smaller than the national average of $2.9 \mathrm{~kW}$ (BEIS, 2017c). Given this, average yield was $996 \mathrm{kWh} / \mathrm{kWp}$, slightly higher than the $894 \mathrm{kWh} / \mathrm{kWp}$ that would be expected for systems of this size if they were performing as per the national average (BEIS, 2016b).

While the households with PV had higher gross electricity demand than the average household, their net demand ( $2424 \mathrm{kWh} / \mathrm{yr}$ ) was lower than the average due to the PV generation. It would be incorrect, however, to assume that lower net demand, in itself, necessarily means households with PV are less dependent on the grid. Indeed, the results show that due to their non-time-coincidence, the average amount that PV generation reduces imports from the grid (the self-consumption) was $855 \mathrm{kWh} / \mathrm{yr}$, meaning the households with PV import almost as much as the control group ( $3515 \mathrm{kWh} / \mathrm{yr}$ vs. $3570 \mathrm{kWh} / \mathrm{yr}$ ). This illustrates how using time-averaged data for PV generation and demand can lead to underestimations of imports and exports (see Appendix 9.2).

Figure 4 illustrates our results, showing mean annual power flows, PV generation, and self-consumption across our sample of solar PV households. We present our own estimates (bars outlined in red) compared with those reported in official publications (bars outlined in black) (CLNR, 2013, 2014b, 2014c). Numbers superimposed on the bars show the estimated mean annual values for all households ( $k W h / y r)$. Percentages superimposed show relative differences between our own estimates relative to official estimates. Our own estimates of PV generation, net demand, and gross demand agree closely with official estimates, which provides confidence in the method we used to prepare the data and construct the related measurements. Slight differences between the two should be expected as the official results make use of data from 2013 only, while here we make use of the full date range of the data (see Appendix 9.1).

On the other hand, we find marked discrepancies between our own estimates and official estimates for imports, exports, and self-consumption: ours are $23 \%$ higher for imports, $179 \%$ higher for exports, and $42 \%$ lower for self-consumption. The discrepancies can be explained by a slight difference in methodologies. The official estimates are based on a 'sum of averages' approach to calculating the derived variables, while our own estimates are based on an 'average of sums' approach, which more accurately captures the average household-level self-consumption. The 'sum of averages' approach, on the other hand, calculates the derived variables from household-averaged PV generation and net demand profiles, which underestimates imports and exports (and over-estimates self-consumption) compared to an 'average of sums' approach based on 'non-household-averaged' data. 'Non-averaged' data here refers to data on generation and power flows that has not been averaged across households, so that calculations of imports and exports are based on 1 min net demand time-series for each individual household. These household-level 1-minute calculations are then summed for each household and averaged across households. This difference between this approach and the other 'sum of averages' approach can be interpreted as the difference between 'after diversity' and nondiversified estimates, the former of which is appropriate when considering the impact of PV from a network perspective (e.g. on substation power flows) while the latter is appropriate when considering the impact of PV from a household's perspective (e.g. on reducing electricity bills). See Appendix 9.2 for further details about potential errors caused by using time- or household-averaged data. We use our own estimates (based on non-averaged data) for the rest of the paper. 


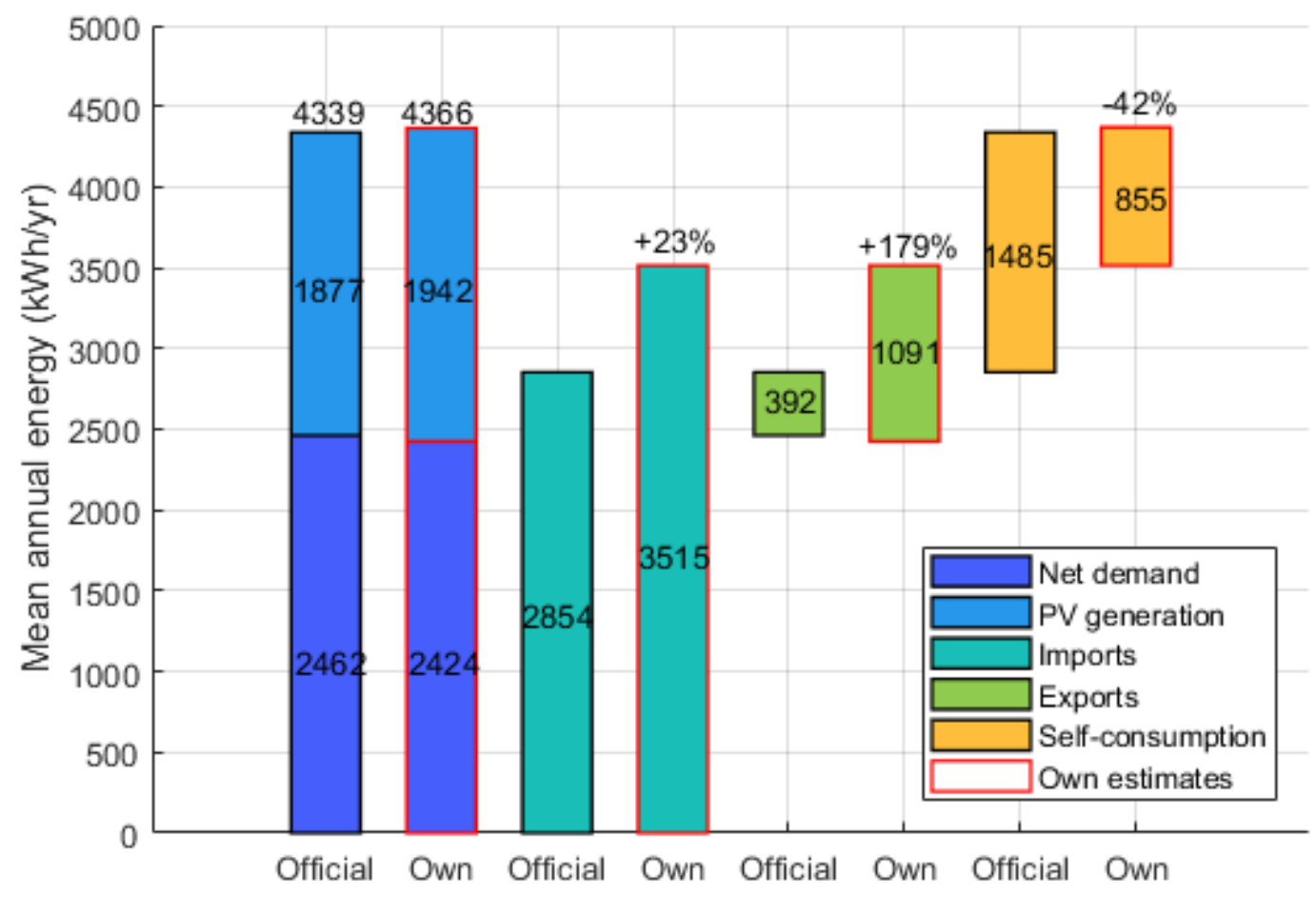

Figure 4 - comparison of official and own estimates for sample of solar PV households. Estimates for exports and self-consumption are shown in a 'waterfall' style to allow visual inspection that the totals 'add up' i.e. imports minus exports equals net demand, imports plus self-consumption equals gross demand, and exports plus self-consumption equals PV generation.

To explore the extent to which CLNR households with PV might be representative of households with PV more generally in the UK, we now compare our results with those of a comparable, though older, dataset: the UK Photovoltaic Domestic Field Trial ("DFT") (Leicester et al., 2016; Munzinger et al., 2006). The DFT was conducted circa 2005 and consisted of a monitoring campaign of several hundred households with PV in the UK over several years. Figure 5 compares histogram distributions of mean annual relative self-consumption for the two groups and is based on our own estimates of self-consumption for 188 households included in the DFT dataset. While the DFT pre-dates the UK feed-in tariff, the majority of participants would have had a similar incentive to maximise self-consumption as households on the feed-in tariff since consumers are compensated for generation (the bulk of the feed-in tariff subsidy) despite how much is self-consumed (McKenna, 2013, p. 138). The data shows that the mean self-consumption for the two groups is quite similar: $44.8 \%$ for CLNR versus $41.5 \%$ for DFT, which provides us with confidence that the sample used in our main analysis (the CLNR data) is representative of PV adopters in the UK more broadly. 


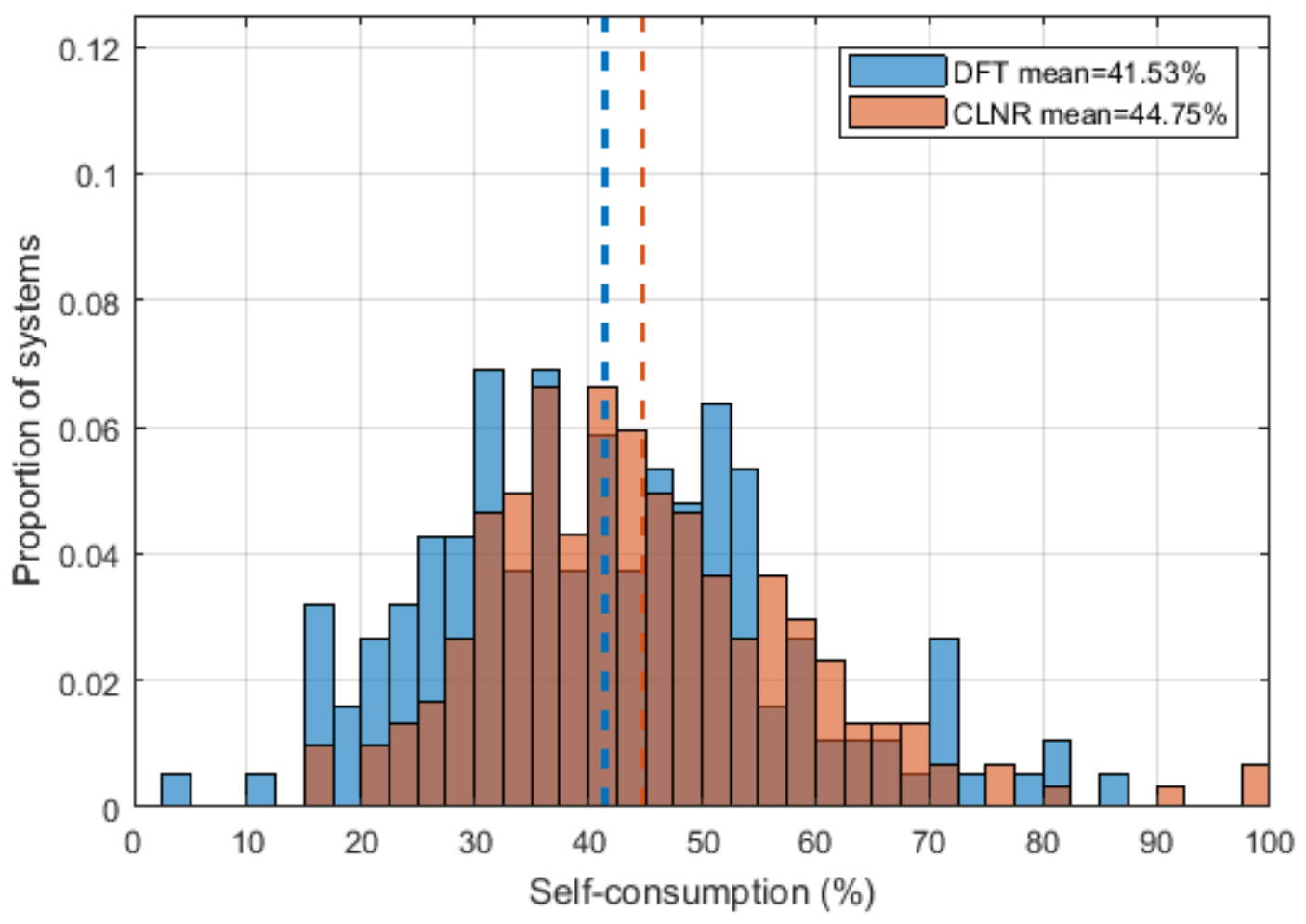

Figure 5 - comparison of results for UK PV DFT ( $N=188, c .2005)$ \& $\operatorname{CLNR}(\mathrm{N}=302, \mathrm{c.2013})$.

The range in self-consumption (Figure 5 ) is large, which illustrates that there is significant diversity in selfconsumption levels between households. The CLNR project conducted 46 interviews with households to investigate behaviour and electricity use patterns in an effort to qualitatively understand how PV affects lifestyles and self-consumption (Bulkeley et al., 2015). The findings indicate that many factors influence levels of self-consumption and demand response: conventions (shared understandings of normal usage), capacities (potential to provide energy services), rhythms of activity, economics (resource management) and the structures of everyday life (Powells and Bulkeley, 2015). Although we cannot quantitatively assess the impact of these factors on self-consumption, we further explore the heterogeneity in self-consumption in the following sections.

We focus on heterogeneity with respect to system size and day-time electricity usage (a proxy for day-time occupancy) as these are factors that we observe, which intuitively affect self-consumption, and are relevant factors that prospective adopters may consider when making investment decisions. The effect of different feed-in tariff incentives is also relevant when considering heterogeneity of self-consumption, however all households in this sample have the same incentive (self-consumption is free) and so this cannot be tested in this context. 


\subsection{Heterogeneity in self-consumption: system size}

Figure 6 shows the relationship between self-consumption, PV generation and gross demand. Data points are annual estimates for each individual CLNR household. The top two graphs show absolute and relative selfconsumption against PV generation, with the colour indicating gross demand. The bottom two graphs show self-consumption against gross demand, with generation level indicated by colour. The data show that absolute self-consumption ( $\mathrm{kWh} / \mathrm{yr}$ ) generally increases with increasing levels of PV generation and increasing levels of gross demand; on average households that consume more or have larger PV systems can expect to self-consume more than households that consume less or have smaller PV systems. With regards to relative levels of self-consumption (\%) the data show this generally increases with gross demand, and decreases with PV generation. The marginal self-consumption value of PV generation decreases with greater amounts of PV generation, suggesting that smaller PV systems are more economic than larger systems from the self-consumption perspective, on average.
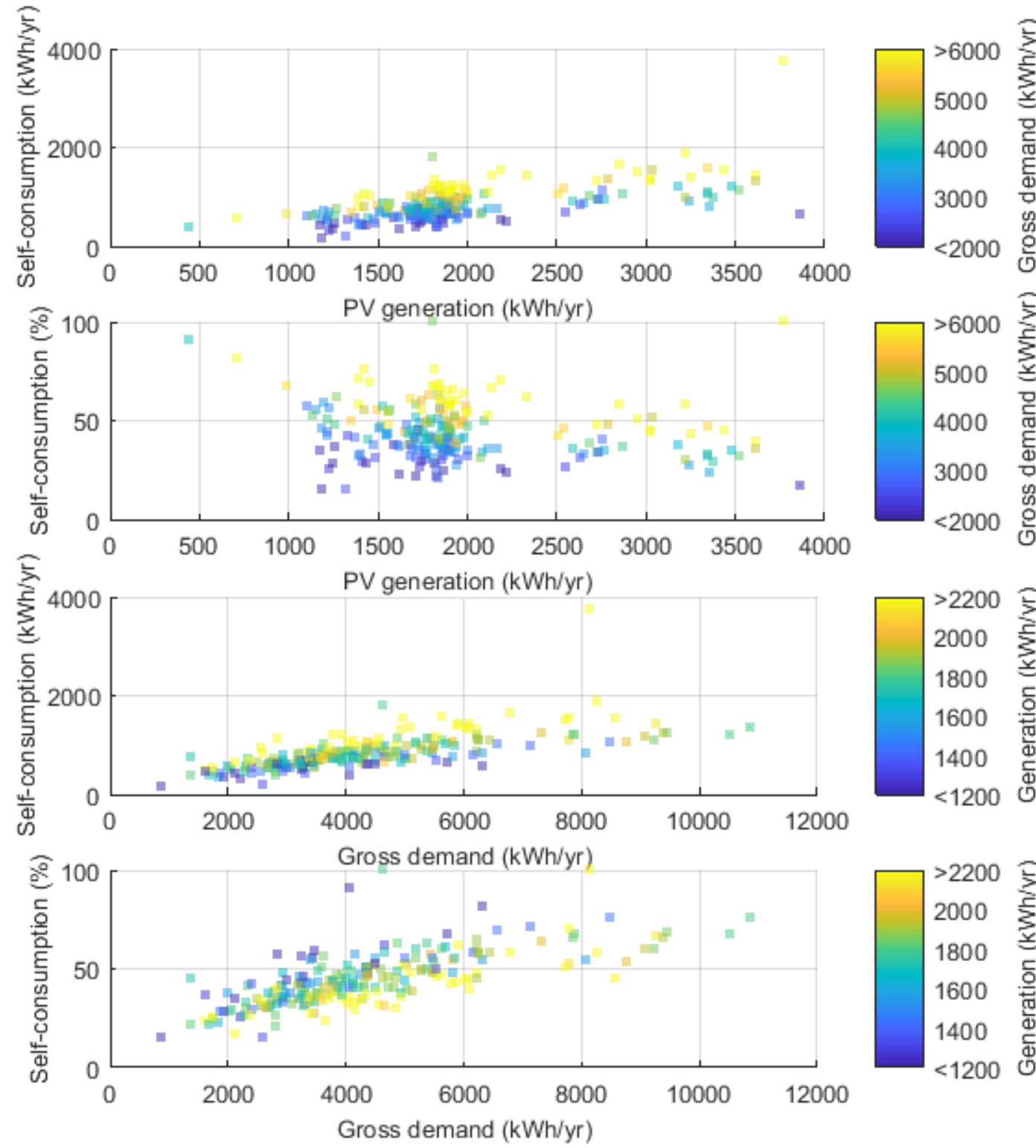

Figure 6 - effect of PV generation and gross demand on self-consumption (absolute and relative). 
The heterogeneity in self-consumption based on PV system size can be seen also in Figure 7, which shows distributions and mean self-consumption for different ranges of PV generation that can be approximated to PV systems of different typical sizes ( $2 \mathrm{~kW}, 3 \mathrm{~kW}$, and $4 \mathrm{~kW}$ ). Mean self-consumption decreases with larger PV systems, and there is considerable heterogeneity around the mean for all system sizes. The average size of PV system installed in the UK is $2.9 \mathrm{~kW}$ (BEIS, 2017c), which would have self-consumption of approximately $42 \%$.

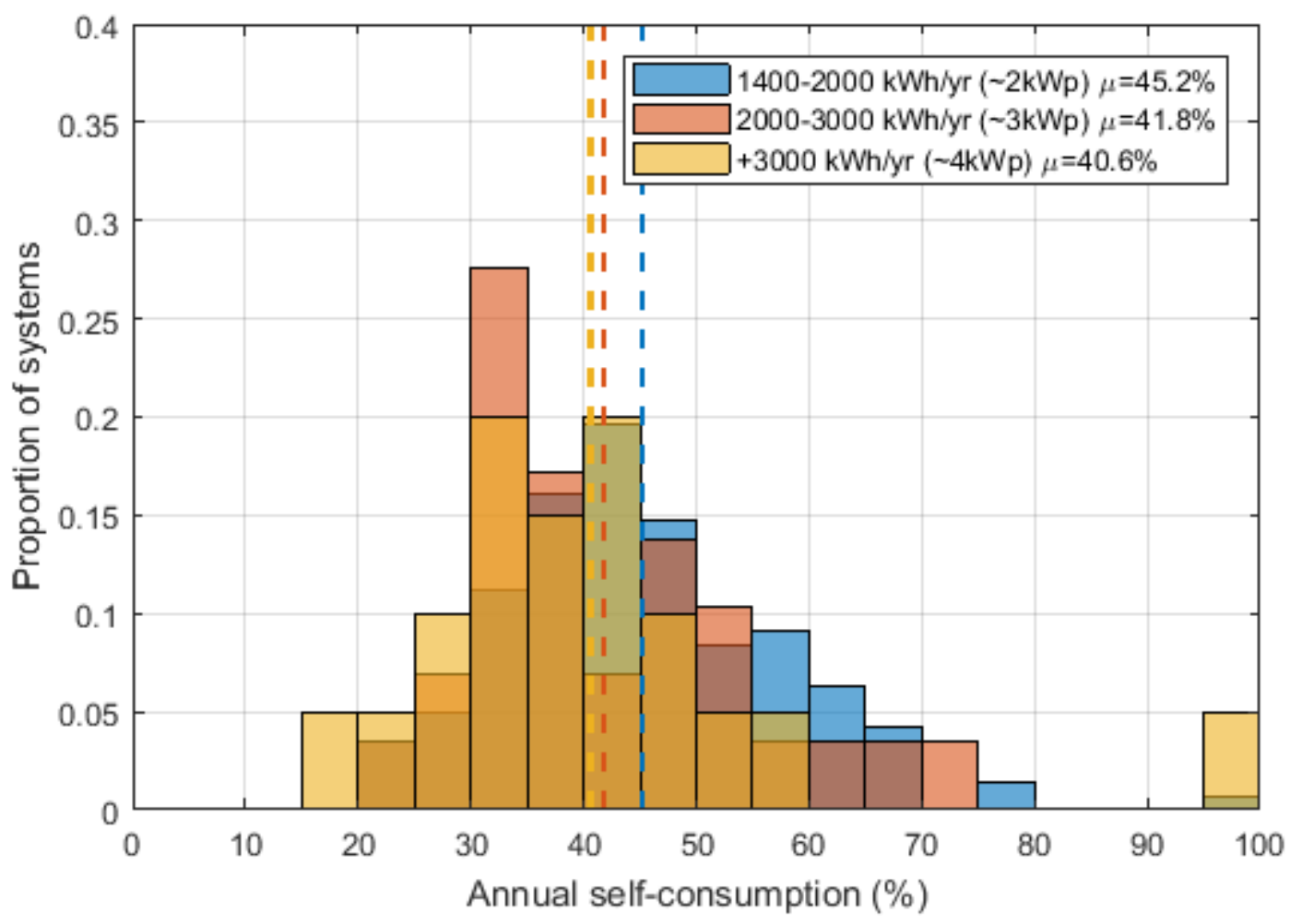

Figure 7 - self-consumption for typical sizes of residential PV systems. 
3.3 Heterogeneity in self-consumption: day-time electricity usage

CLNR found a higher proportion of electricity use during the day-time (10am to $4 \mathrm{pm}$ ) for the PV test cells compared to the control group (CLNR, 2013). This indicates that the households with PV have electricity demand profiles that are better aligned with PV generation than the average household. This could be because the households with PV made changes to their patterns of electricity consumption to take advantage of the opportunity to consume cheap electricity from their PV, or that they had lifestyles that were already well-aligned e.g. high day-time occupancy, retired households, high levels of energy awareness and an interest in self-sufficiency, which could have influenced their decision to adopt solar in the first place. To test whether self-consumption differs based upon day-time electricity usage, we found the average fraction of day-time electricity usage for each household with PV and split the sample into three groups: low, typical, and high fraction day-time electricity users. The control group had a fraction of day-time electricity use of 0.267 (CLNR, 2014a) and "typical" use was therefore assumed to be between 0.25 and 0.28. Low and high fractions were those falling outside this range. Figure 8 shows the results. As expected, there are a higher number of households with high fraction day-time electricity usage for the PV consumers (162, compared to 66 typical and 56 low). Households with PV and fractions of day-time electricity usage typical to the control group have a self-consumption level of $43 \%$, which gives an indication of what self-consumption levels might be expected for a typical UK household (as opposed to one that has already installed PV).
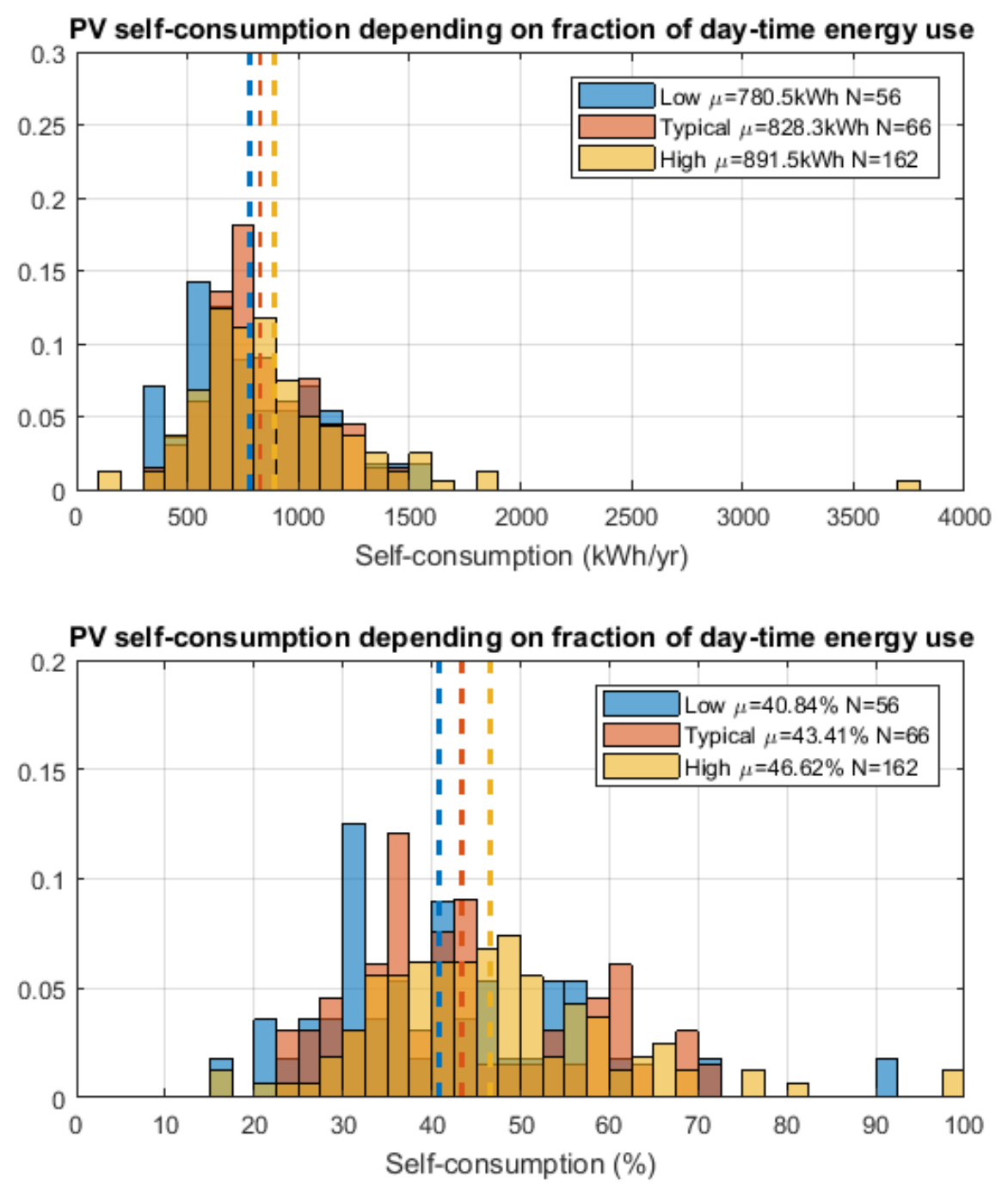

Figure 8 - levels of self-consumption for different levels of day-time electricity use. 'Typical' is consistent with the average of the CLNR control group. 


\section{Annual self-consumption for a typical UK household with PV}

This section estimates annual self-consumption for a typical household with PV in the UK based on the regression analysis of the CLNR PV data described in Section 2. Table 2 shows the results of the estimation (Equation 1). The coefficient estimates for PV generation and the fraction day-time usage times gross demand are statistically significant at the $0.01 \%$ level, suggesting that the variables included are strongly correlated with self-consumption. The adjusted $\mathrm{R}$-squared is 0.754 , which provides us with confidence that our simple model explains a large portion of the variation in the data.

Table 2 - Self-Consumption Regression Estimates

\begin{tabular}{lc} 
PV Generation & $0.298 * * *$ \\
& $(0.021)$ \\
Gross Demand * Fraction day-time usage & $0.381^{\star * \star}$ \\
& $(0.021)$ \\
& \\
Intercept & $-212.95^{\star * *}$ \\
& $(45.74)$ \\
\hline Number of Observations & 218 \\
R-Squared & 0.757 \\
Adjusted R-Squared & 0.754 \\
Root Mean Squared Error & 177 \\
\hline
\end{tabular}

Note: Asterisks denote ${ }^{*} p<0.10,{ }^{* *} p<0.05,{ }^{* \star *} p<0.01$

Figure 9 provides a visual representation of the 'goodness of fit' of the regression model. The figure shows the model's estimate of self-consumption for the CLNR households against actual self-consumption. Estimates are shown with 95\% confidence interval error bars. A 1:1 line of 'perfect fit' is shown for comparison. There is clearly some scatter and discrepancy between predicted and actual self-consumption, particularly for extreme values, however there is reasonably good agreement on average given the simplicity of the model. 


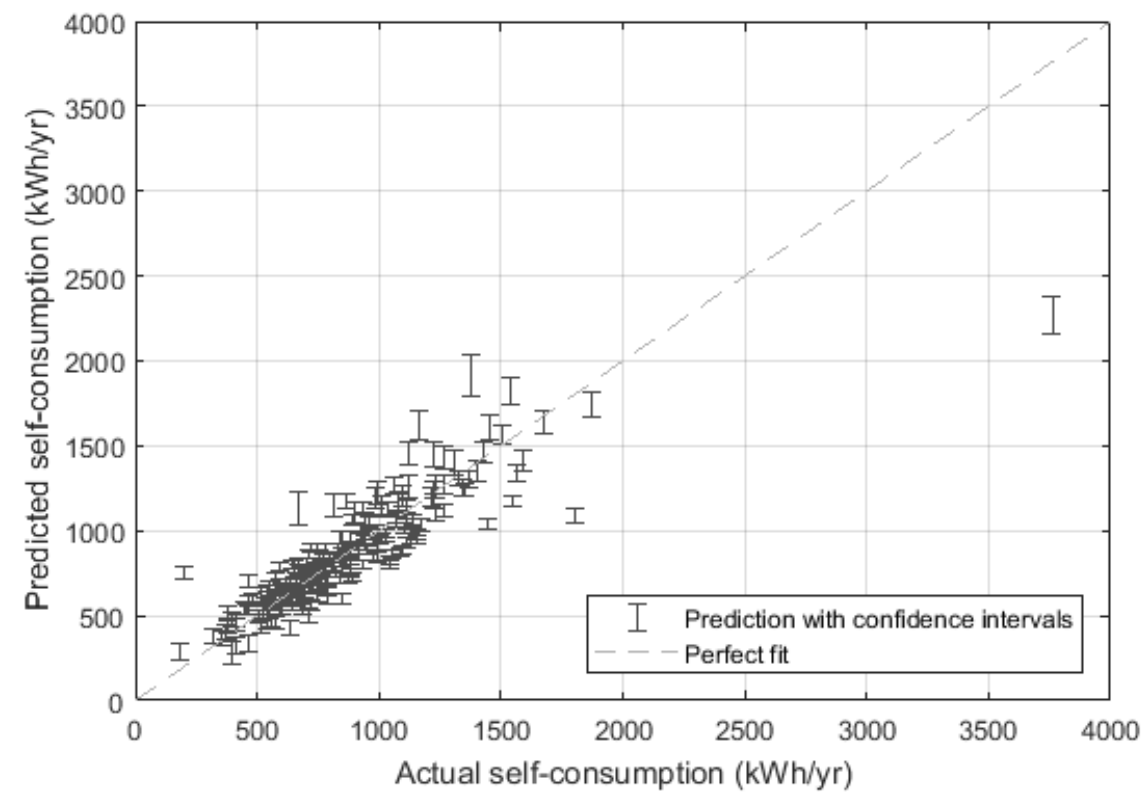

Figure 9 - results of regression estimation. Predicted values are shown with individual confidence intervals against actual self-consumption. A line of 'perfect fit' is shown for comparison.

Finally, we use our regression estimates to predict annual self-consumption and the implied electricity demand reductions for a typical household and PV system in the UK. We assume that self-consumption is equivalent to bill savings (reductions in imports) and that the test cells are representative of households installing PV. The average size of residential PV in the UK is $2.9 \mathrm{~kW}$ (BEIS, 2017c), and average load factor for $\mathrm{PV}$ is 10.2\% (BEIS, 2016b). We use the UK annual gross electricity demand for 2015 of $4000 \mathrm{kWh} / \mathrm{yr}$ (BEIS, 2017e) and fraction day-time electricity usage of 0.267 based on CLNR control group TC1a (CLNR, 2014a). Using these input values, the model above predicts annual self-consumption of $966 \pm 38 \mathrm{kWh} / \mathrm{yr}$, or $37.3 \% \pm$ $1.5 \%$. This corresponds to a reduction of $24 \%$ on the typical grid electricity demand of $4000 \mathrm{kWh} / \mathrm{yr}$. Assuming a cost of electricity of $15 \mathrm{p} / \mathrm{kWh}$, this implies electricity bill savings of $£ 138 /$ year per household, on average.

This is approximately twice the estimate given in the UK Government's analysis of the National Energy Efficiency Data (NEED) framework, which indicates average bill savings for PV of $500 \mathrm{kWh} / \mathrm{yr}$ (BEIS, 2017e) or $£ 75 / \mathrm{yr}$ at $15 \mathrm{p} / \mathrm{kWh}$. We note two shortcomings that make direct comparison of these estimates challenging. Firstly, given the lack of socio-demographic data available for them, the CLNR PV group may well be unrepresentative of PV owners more generally. Secondly, the NEED estimate is based on import meter readings for households with $\mathrm{PV}$, not net demand readings. Without the latter, it is not possible to determine the gross demand of households after installing PV, nor their self-consumption. This complicates their comparison with any control group (e.g. to determine if there is a rebound effect with PV) or with the CLNR group. 


\section{Conclusions and policy implications}

Estimating and predicting solar PV self-consumption is increasingly important in many markets as it is becoming the main economic driver of solar adoption in the face of falling subsidies. However, there is remarkably little empirical evidence thus far in the literature regarding the levels and determinants of selfconsumption. Our analysis of a sample of UK households with PV shows self-consumption levels of $855 \mathrm{kWh} / \mathrm{yr}$ or $45 \%$ of generation on average. This finding, which examines self-consumption from the household's perspective, is considerably lower than the official estimates provided by the CLNR project, which examines self-consumption from the overall network perspective. For an accurate calculation of imports, exports and self-consumption (from the household's perspective), PV generation and net demand data of sufficiently high resolution is required. Averaging over time and multiple households is likely to underestimate imports and exports and over-estimate self-consumption compared to non-averaged data. Furthermore, estimating self-consumption from the household's perspective provides valuable information to solar consumers, policymakers, and industry in the context of valuing solar investments, setting feed-in tariffs, marketing solar systems to new customers, and examining the impacts of self-consumption on the grid.

We also estimated self-consumption as a function of PV generation, gross demand, and their timecoincidence. We found that self-consumption is predicted to be $966 \pm 38 \mathrm{kWh} / \mathrm{yr}(37.3 \% \pm 1.5 \%$.) for an average UK household (gross electricity demand of $4000 \mathrm{kWh} / \mathrm{yr}$ ) and average UK PV system of $2.9 \mathrm{~kW}$. This corresponds to a reduction of the average UK household's annual electricity demand of $24 \%$, which implies savings of $£ 138 / \mathrm{yr}$ per household (assuming a cost of electricity of $15 \mathrm{p} / \mathrm{kWh}$ ).

This paper has shown that there is considerable evidence on PV self-consumption in the UK residential sector on which to base UK solar policy. The UK government's choice of a self-consumption rate of $45 \%$ happens to be identical to the self-consumption observed with the CLNR households with PV. These households however have higher gross electricity demand and higher fraction of day-time electricity usage than the average, both of which lead to higher levels of self-consumption than what would be expected for the average UK household. An appropriate rate of self-consumption to reflect the average sized PV system (2.9 kW) and average household with gross electricity demand of $4000 \mathrm{kWh} / \mathrm{yr}$ and typical fractions of day-time electricity usage would be $37.3 \%$, not $45 \%$. For the purposes of receiving feed-in tariff payments, households with PV in the UK are currently deemed to export $50 \%$ of what they generate (regardless of actual exports); if exports continue to be unmetered, it is arguable that a deemed percentage of 55\%-63\% would more accurately reflect actual exports.

There are many avenues moving forward that are ripe for future research, particularly as self-consumption becomes a more important driver of solar adoption in markets around the world. First, this paper focused on self-consumption in the UK, however behaviour may differ in other markets and thus an international comparison of self-consumption would be useful to better understand what drives self-consumption, particularly when taking into account the different financial incentives for self-consumption. Relatedly, sociodemographic data was unavailable for this analysis, although it would be valuable to explore different types of sociodemographic heterogeneity in self-consumption. Furthermore, this paper focussed on self-consumption in the absence of 'enabling technologies' such as batteries or electric vehicles, but investigating the impact of these technologies on self-consumption would also be useful.

Lastly, while average levels of self-consumption have been the focus of this paper and are significant for solar investment valuation and policy, the wide range of potential energy and financial outcomes from PV installation is an important consideration. As such, exploring more of the heterogeneity in self-consumption in general is important for being able to refine estimations and predictions of self-consumption. This is particularly important for industry and the marketing of PV as firms ask what types of households are most likely to be able to benefit from self-consumption in terms of their capacity, occupancy, and electricity use characteristics. It will also have implications for developing social and personal responses to the availability of electricity at different times of the day and year. 


\section{Acknowledgements}

The authors gratefully acknowledge funding from the Oxford Martin School through the Oxford Martin Programme on Integrating Renewable Energy. The Oxford Martin School is a world-leading centre of pioneering research that addresses global challenges. Visit: www.oxfordmartin.ox.ac.uk for more information.

The authors gratefully acknowledge use of data from the Customer-Led Network Revolution which is available free of charge under the Creative Commons Attribution-ShareAlike Licence. The partners involved in the Customer-Led Network Revolution were Northern Powergrid, British Gas, EA Technology, Durham University, and Newcastle University.

\section{Declaration of interest}

Conflict of interest: none.

\section{References}

Arup, 2011. Review of the generation costs and deployment potential of renewable electricity technologies in the UK: Study report by ARUP.

BEIS, 2017a. Energy and Climate Change Public Attitudes Tracker: Wave 22.

BEIS, 2017b. National Statistics - Solar photovoltaics deployment.

BEIS, 2017c. National Statistics - Monthly feed-in tariff commissioned installations.

BEIS, 2017d. Updated energy and emissions projections: 2016.

BEIS, 2017e. National Energy Efficiency Data-Framework (NEED) report: summary of analysis 2017.

BEIS, 2016a. Electricity Generation Costs (November 2016).

BEIS, 2016b. Energy Trends: Dectember 2016, special feature article - Feed-in Tariff load factor analysis, 2011/12 to 2015/16.

Bulkeley, H., Whitaker, G., Matthews, P., Bell, S., Lyon, S., Powells, G., 2015. High Level Summary of Learning: Solar PV Customers.

Carbon Tracker, Grantham Institute, 2017. Expect the Unexpected: The Disruptive Power of Low-carbon Technology.

CLNR, 2017. Project Data - Customer-Led Network Revolution.

CLNR, 2014a. Dataset (TC1a): Basic Profiling of Domestic Smart Meter Customers.

CLNR, 2014b. Dataset (TC5): Enhanced Profiling of Domestic Customers with Solar Photovoltaics (PV).

CLNR, 2014c. Dataset (TC20 IHD): Domestic solar PV customers using in-home displays for manual inpremises balancing.

CLNR, 2013. Insight Report: Domestic Solar PV Customers.

DECC, 2016. Historical electricity data: 1920 to 2015.

DECC, 2015a. Impact Assessment: Government response to consultation on a review of the Feed-in Tariff scheme.

DECC, 2015b. Consultation on a review of the Feed-in Tariff scheme.

DECC, 2015c. National Energy Efficiency Data-Framework (NEED) report: summary of analysis 2015. Annex B: Electricity use in households with solar PV panels.

DECC, 2013. Electricity Generation Costs 2013.

Edenhofer, O., Pichs-Madruga, R., Sokona, Y., Farahani, E., Kadner, S., Seyboth, K., Adler, A., Baum, I., Brunner, S., Eickemeier, P., others, 2014. Climate change 2014: Mitigation of climate change. Contrib. Work. Group III Fifth Assess. Rep. Intergov. Panel Clim. Change 511-597.

Labastida, R., 2017. Self-Consumption Markets Are the Future of Solar.

Leicester, P.A., Goodier, C.I., Rowley, P.N., 2016. Probabilistic analysis of solar photovoltaic self-consumption using Bayesian network models. IET Renew. Power Gener. 10, 448-455.

McKenna, E., 2013. Demand response of domestic consumers to dynamic electricity pricing in low-carbon power systems (Thesis).

McKenna, E., Thomson, M., 2014. Demand response behaviour of domestic consumers with photovoltaic systems in the UK: an exploratory analysis of an internet discussion forum. Energy Sustain. Soc. 4, 1 12.

McKenna, E., Thomson, M., 2013. Photovoltaic metering configurations, feed-in tariffs and the variable effective electricity prices that result. IET Renew. Power Gener. 1-11. https://doi.org/10.1049/ietrpg.2012.0268

Munzinger, M., Crick, F., Dayan, E., Pearsall, N., Martin, C., 2006. PV Domestic Field Trial: Final Technical Report. Accessed on 10th December 2012.

National Grid, 2017. Demand Turn Up. 
NPG, 2017. Customer-Led Network Revolution.

Ofgem, 2017. Feed-in Tariff (FIT): Tariff Table 1 April 2017.

Pfeiffer, A., Millar, R., Hepburn, C., Beinhocker, E., 2016. The '2 C capital stock'for electricity generation: Committed cumulative carbon emissions from the electricity generation sector and the transition to a green economy. Appl. Energy 179, 1395-1408.

Powells, G., Bulkeley, H., 2015. Key Social Science Findings: Domestic and SME Customers.

Taylor, M., Daniel, K., llas, A., So, E.Y., 2015. Renewable power generation costs in 2014. Int. Renew. Energy Agency Masdar City Abu Dhabi UAE.

Urquhart, A.J., Thomson, M., 2015. Impacts of Demand Data Time Resolution on Estimates of Distribution System Energy Losses. Power Syst. IEEE Trans. On 30, 1483-1491. https://doi.org/10.1109/TPWRS.2014.2349157

Widén, J., Wäckelg\a ard, E., Paatero, J., Lund, P., 2010. Impacts of different data averaging times on statistical analysis of distributed domestic photovoltaic systems. Sol. Energy 84, 492-500.

WPD, 2016. Distributed Generation Stakeholder Workshop.

\section{Appendix}

\subsection{Data preparation}

Filters were used when querying the data to avoid any obvious errors. Readings that showed PV generation or exports (negative net demand) greater than $5 \mathrm{~kW}$ were ignored (residential PV systems are limited to $4 \mathrm{~kW}$ in the UK), as well as any readings that were exactly zero - this was taken to indicate an error in recording rather than a true value. Some households showed consistently negative values for PV generation - these readings were reversed.

Secondly, some systems had days with missing minutes, months with missing days, years with missing months, etc. Clearly this affects the ability to compare results between different systems. The gaps in the data were therefore evaluated and data that was too 'gappy' was rejected, with remaining data scaled to provide estimates over comparable units of time, as detailed in the following.

In our analysis, we aggregate the data to the annual level. At each step of the process, the data was checked for gaps. Gaps were estimated by counting the number of data points for generation and net demand for each system. Days with less than $98 \%$ data availability were discarded (i.e. missing $2 \%$ of 1 min data). Remaining 'accepted' data was scaled up to provide comparable estimates for the time period in question (day/month/year). This resulted in approximately $10 \%$ rejection. For the remaining data, daily sums were calculated for the variables of interest and these scaled according to "daily availability factors" - the number of observations per day divided by the total number of minutes per day - to provide comparable 'whole day' estimates. Months with less than $60 \%$ availability of days were rejected, which accounted for approximately $20 \%$ of the monthly data. The scaled daily data was then used to calculate monthly data for each system, again scaled to provide comparable 'whole month' data.

The presence of missing (rejected) data was not uniform in time nor across systems. Figure 10 shows the number of monthly data points that were available throughout the trial (black line, left axis), and the average availability of data for each of these (solid blue line, right axis). Figure 10 also shows the proportion of monthly data points that could not be used, either because there was no data for the system, or the data point was rejected. 


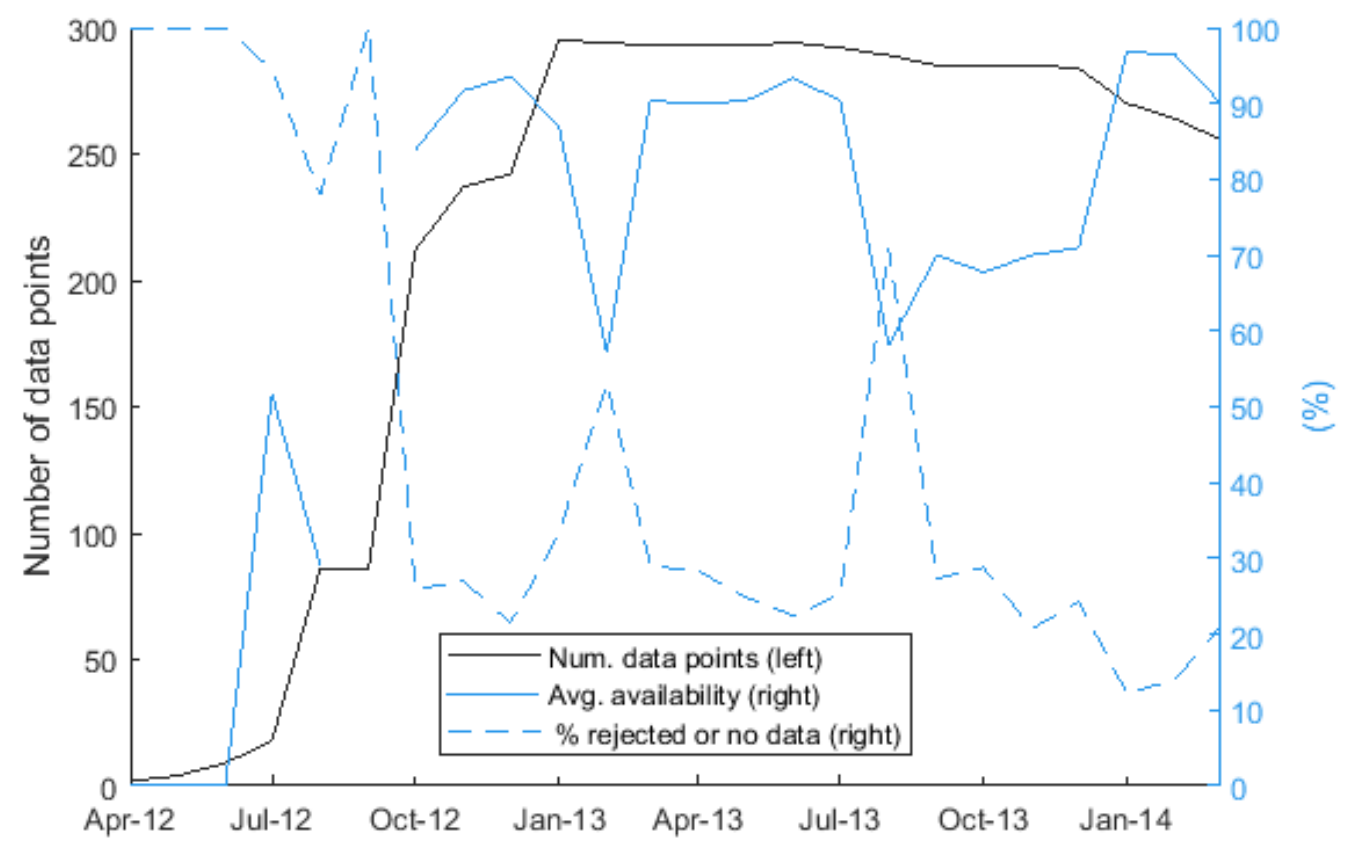

Figure 10 - variation of availability of monthly data points throughout the duration of the trial, and proportion of data rejected due to insufficient number of days of data for each monthly data point.

Monthly data was then used to estimate annual values for each system. Figure 11 shows the number of data points for each month of the year for each system. Where no data was available for a specific month, but data was available for adjacent months, linear interpolation was used to estimate the missing month's data. This helped fill some of the gaps in monthly data. Where more than one month of data was available, a mean value was used. In coming up with the annual values for each system, if less than $70 \%$ of monthly data was available for estimating the annual totals for a given system, then the system's data was rejected, otherwise the values were scaled up accordingly to provide 'whole year' annual estimates for each system. 


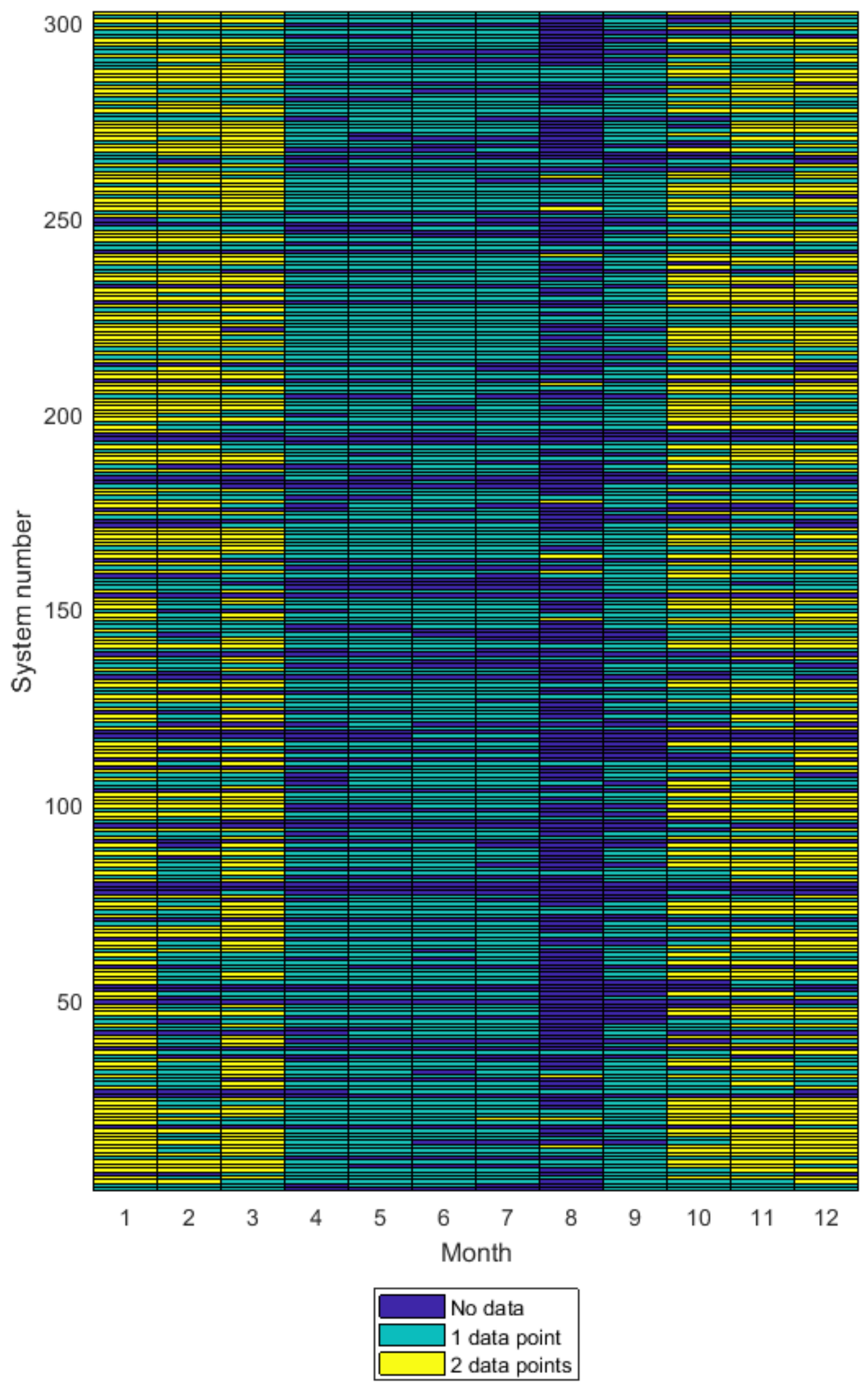

Figure 11 - number of data points for each month and each system (Month 1 = January). 


\subsection{Note on the use of time or space-averaged data}

A minimum of two electricity meters are required to calculate the derived variables in Table 1, typically one to record PV generation and another to record the net demand profile. However it is important to note that to produce accurate calculations for the derived variables the meters need to be measuring data at sufficiently high time-resolution (Widén et al., 2010). This is because calculating imports, exports, and self-consumption from generation and demand data depends not only on how much is being generated and consumed, but also their time-coincidence. Higher time resolution allows more accurate assessment of time-coincidence, and this is particularly important if the data is 'spikey', as is often the case with residential electricity demand (e.g. in Figure 3). For example, if two meters recording at one-hour resolution show that for a specific hour $1 \mathrm{kWh}$ was generated and $1 \mathrm{kWh}$ was consumed, then it could be possible that $1 \mathrm{kWh}$ was exported and $1 \mathrm{kWh}$ imported (and self-consumption was $0 \mathrm{kWh}$ ), or that nothing was exported and nothing imported (and selfconsumption was $1 \mathrm{kWh}$ ), or indeed something in between these two extremes. High resolution, non-time averaged data is therefore important when calculating derived variables such as imports, exports, and selfconsumption.

By way of example, Figure 12 (top) quantifies the error in calculating imports and exports for one month of PV generation and net demand data for the same single residential household with PV in the UK shown previously in Figure 3. The graph shows the difference in estimates of imports and exports between the original 1-minute resolution data, and data that has been progressively time-averaged, up to a maximum averaging period of a day. This illustrates that using data averaged over 30 min (a typical resolution for smart meters) can significantly underestimate the calculation of imports and exports, around $15 \%$ for the specific month of data chosen here. Due care should therefore be taken when calculating derived variables using data with low time-resolution. This paper's analysis is based on data at 1 min resolution. See (Urquhart and Thomson, 2015; Widén et al., 2010) for further discussion on this topic. 

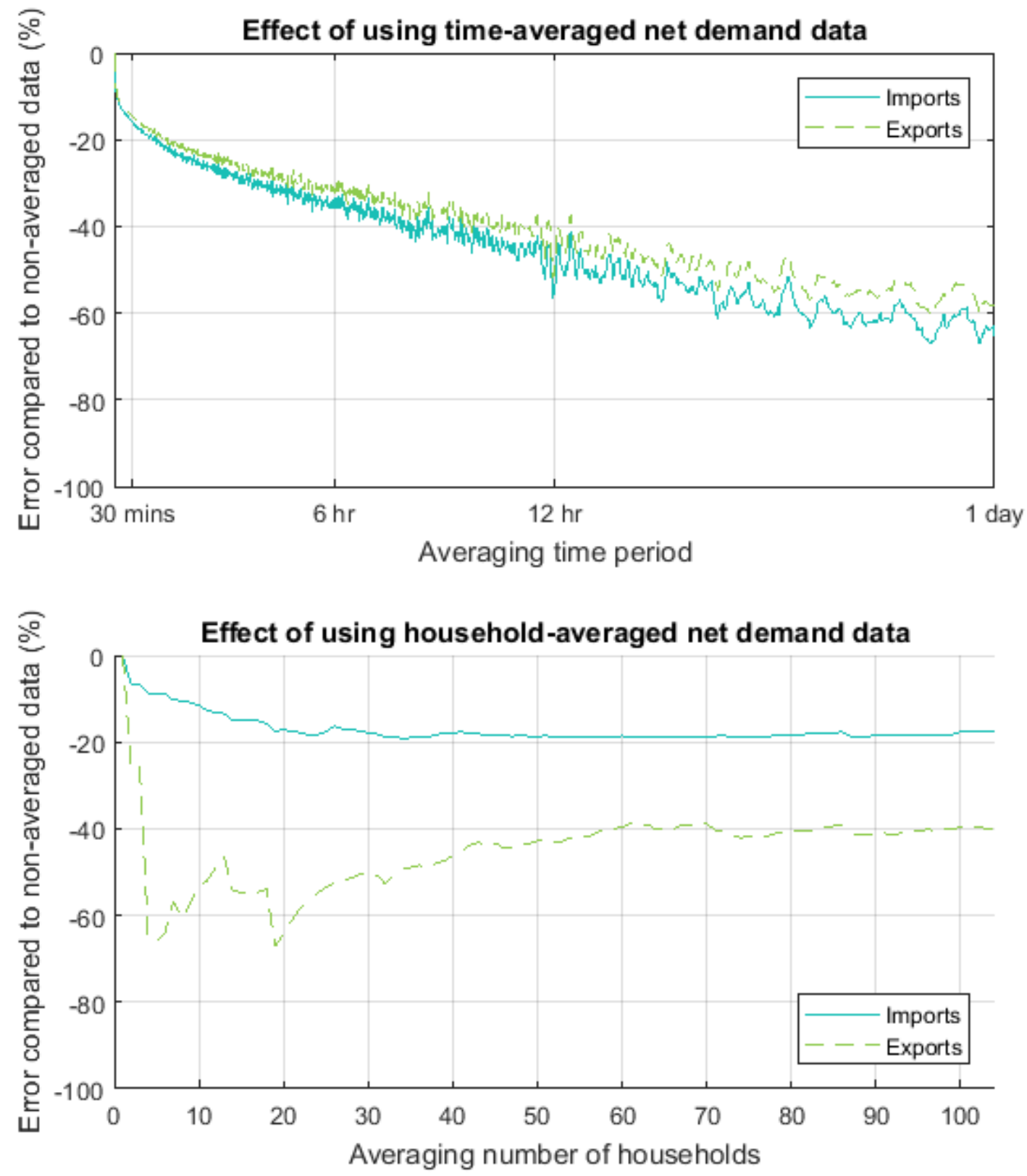

Figure 12 - Examples of how calculations of imports and exports (and self-consumption) can be underestimated when using time-averaged (top figure) or household-averaged (bottom figure) net demand data. 
A similar issue arises when deriving variables such as self-consumption using PV generation and net demand data that has been averaged over multiple households (averaged in space rather than time). Figure 12 (bottom) provides a similar quantification of the effect of using time-averaged data as above but this time using 1-minute time-coincidence data that has been averaged over multiple households, up to 100 households. 'Non-averaged' data here refers to non-household-averaged data, and consists of calculations of imports and exports that are based on 1 min net demand time-series for each individual household, summing the imports and exports for each of these, and taking the mean. This is the 'average of sums'. In the figure this is compared with 'household-averaged' data, which consists of calculating mean net demand profiles for the number of households in question, and then summing the imports and exports of this average profile. In other words, the 'sum of averages'. The figure above shows how the sum of averages approach underestimates imports and exports (and therefore also overestimates self-consumption). This paper uses an average of sums approach which avoids this underestimation of imports and exports. 